\title{
Correction of serum potassium with sodium zirconium cyclosilicate in Japanese patients with hyperkalemia: a randomized, dose-response, phase $2 / 3$ study
}

\author{
Naoki Kashihara ${ }^{1} \cdot$ Toshiki Nishio $^{2} \cdot$ Takeshi Osonoi $^{3} \cdot$ Yosuke Saka $^{4} \cdot$ Toshiyuki Imasawa $^{5} \cdot$ Takayasu Ohtake $^{6}$. \\ Hiroshi Mizuno $^{7} \cdot$ Yugo Shibagaki $^{8} \cdot$ Hyosung Kim $^{9} \cdot$ Toshitaka Yajima $^{9} \cdot$ Nobuaki Sarai $^{9}$ (i)
}

Received: 29 April 2020 / Accepted: 19 July 2020 / Published online: 10 August 2020

(c) The Author(s) 2020

\begin{abstract}
Background Sodium zirconium cyclosilicate (SZC) is an oral potassium binder approved to treat hyperkalemia in adults in a number of countries, including Japan.

Methods This phase 2/3, randomized, double-blind, placebo-controlled, dose-response study (ClinicalTrials.gov: NCT03127644) was designed to determine the efficacy and safety of SZC in Japanese adults with hyperkalemia. Patients with serum potassium $\left(\mathrm{sK}^{+}\right)$concentrations $\geq 5.1-\leq 6.5 \mathrm{mmol} / \mathrm{L}$ were randomized $1: 1: 1$ to SZC $5 \mathrm{~g}$, SZC $10 \mathrm{~g}$, or placebo three times daily for $48 \mathrm{~h}$ (six doses total). The primary efficacy endpoint was the exponential rate of change in sK $\mathrm{K}^{+}$over $48 \mathrm{~h}$. The proportion of patients with normokalemia $\left(\mathrm{sK}^{+} 3.5-5.0 \mathrm{mmol} / \mathrm{L}\right)$ at $48 \mathrm{~h}$ and adverse events (AEs) were also evaluated. Results Overall, 103 patients (mean age, 73.2 years; range 50-89 years) received SZC $5 \mathrm{~g}(n=34)$, SZC $10 \mathrm{~g}(n=36)$, or placebo $(n=33)$. The exponential rate of $\mathrm{sK}^{+}$change from 0 to $48 \mathrm{~h}$ versus placebo was -0.00261 (SZC $\left.5 \mathrm{~g}\right)$ and -0.00496 (SZC $10 \mathrm{~g}$; both $P<0.0001$ ). At $48 \mathrm{~h}$, the proportions of patients with normokalemia were $85.3 \%, 91.7 \%$, and $15.2 \%$ with SZC $5 \mathrm{~g}$, SZC $10 \mathrm{~g}$, and placebo, respectively. No serious AEs were reported. Hypokalemia ( $\mathrm{sK}^{+}<3.5 \mathrm{mmol} / \mathrm{L}$ ) occurred in two patients in the SZC $10 \mathrm{~g}$ group; normokalemia was re-established within 6 days and no treatment-related AEs were reported. Conclusion SZC is effective and well tolerated in Japanese patients with hyperkalemia.
\end{abstract}

Keywords Sodium zirconium cyclosilicate $\cdot$ Hyperkalemia $\cdot$ Japanese $\cdot$ Japan

Electronic supplementary material The online version of this article (https://doi.org/10.1007/s10157-020-01937-1) contains supplementary material, which is available to authorized users.

Nobuaki Sarai

nobuaki.sarai@astrazeneca.com

1 Department of Nephrology and Hypertension, Kawasaki Medical School, Okayama, Japan

2 Nephrology Dialysis Center, Kusatsu General Hospital, Shiga, Japan

3 Department of Internal Medicine, Nakakinen Clinic, Ibaraki, Japan

4 Department of Nephrology, Kasugai Municipal Hospital, Aichi, Japan

\section{Introduction}

Hyperkalemia, a common electrolyte disorder defined by elevated serum potassium $\left(\mathrm{sK}^{+}\right)$, is often associated with comorbidities such as chronic kidney disease (CKD), heart failure (HF), and diabetes [1]. Hyperkalemia is also a common side effect of renin-angiotensin-aldosterone system

5 Department of Nephrology, Chiba-Higashi Hospital, Chiba, Japan

6 Department of Nephrology, Shonan Kamakura General Hospital, Kanagawa, Japan

7 Department of Nephrology, Inage Hospital, Chiba, Japan

8 Division of Nephrology and Hypertension, St. Marianna University School of Medicine Hospital, Kanagawa, Japan

9 Research and Development, AstraZeneca K.K, 1-8-3, Marunouchi, Chiyoda-ku, Tokyo 100-0005, Japan 
inhibitors (RAASi), used in the management of CKD and HF [2-4]. In Japan, the overall prevalence of hyperkalemia in a hospital claims database population was 67.9 patients per 1000; this increased to 227.9, 134.0, 108.4, and 142.2 patients per 1000 in those with CKD, HF, diabetes, and RAASi therapy, respectively [1].

Severe hyperkalemia can cause serious cardiac arrhythmia [5], and is associated with increased all-cause, in-hospital, and cardiovascular death [6-8]. Large observational studies showed a U-shaped relationship between $\mathrm{sK}^{+}$and mortality $[9,10]$, with the 3-year incidence of in-hospital death in Japanese patients lowest with $\mathrm{sK}^{+} 4.0 \mathrm{mmol} / \mathrm{L}$, and the risk of death increasing over seven-fold at concentrations of $5.1-5.4 \mathrm{mmol} / \mathrm{L}$ [1].

Options for managing hyperkalemia in Japan are limited, relying on dietary restrictions, cessation or modification of inciting agents, and potassium elimination with non-specific exchange resins, e.g., sodium polystyrene sulfonate (SPS) and calcium polystyrene sulfonate (CPS) [11, 12]. Although SPS and CPS have been widely used for several decades, their efficacy and safety have been questioned [13-16]. There is a significant need for novel treatments that correct and maintain $\mathrm{sK}^{+}$ within a safe range in Japanese patients with hyperkalemia.

Sodium zirconium cyclosilicate (SZC) is a novel, nonabsorbed, highly selective potassium binder which preferentially entraps potassium ions in the gastrointestinal lumen in exchange for hydrogen and sodium ions [17-19]. Binding of free potassium in the gastrointestinal lumen by SZC increases fecal potassium excretion, consequently lowering $\mathrm{sK}^{+}$concentration $[17,19,20]$. The efficacy and safety of SZC were demonstrated in phase 3 studies of patients with hyperkalemia with and without CKD or HF [18, 20, 21]. In these studies, SZC $10 \mathrm{~g}$ three times daily (TID) reduced mean $\mathrm{sK}^{+}$concentration to within the normal range within $48 \mathrm{~h}$, significantly reducing $\mathrm{sK}^{+}$versus placebo as early as 1-h post-baseline $[18,20]$. Sustained potassium control for up to 1 year has been demonstrated with SZC [18, 20-22]. SZC is currently approved in a number of countries, including Japan, for the treatment of hyperkalemia in adults [23-25].

Phase 3 studies of SZC performed to date included relatively few patients of Asian ethnicity [18, 20, 21]. However, potassium intake varies between different countries and cultures [26]; notably, consumption of potassium in the Japanese population is lower than that of Western countries [27]. Therefore, we performed a phase $2 / 3$ dose-response study to determine the efficacy and safety of SZC in Japanese patients with hyperkalemia.

\section{Methods}

\section{Study design}

This phase $2 / 3$, multicenter, randomized, double-blind, placebo-controlled, dose-response confirmatory study (ClinicalTrials.gov: NCT03127644) was conducted at 24 investigational sites in Japan between June 14, 2017 and February 23, 2018. See Supplemental Materials for ethical permissions and patient consent procedures.

The study comprised a screening visit, a 48-h treatment period, and a 1-week follow-up visit ( \pm 2 days) (Fig. 1). In the treatment period, patients were randomized $1: 1: 1$ to receive double-blind treatment with SZC (5 g or $10 \mathrm{~g}$ ) or placebo TID for $48 \mathrm{~h}$ (six doses total); see Supplemental Materials for details.

\section{Patients}

Eligible patients were adults aged $\geq 18$ years with hyperkalemia, defined as two consecutive potassium concentrations of $\geq 5.1$ to $\leq 6.5 \mathrm{mmol} / \mathrm{L}$, measured $60( \pm 10) \mathrm{min}$ apart and within 1 day before study drug administration, using a point-of-care i-STAT device (Abbott Point of Care, Inc, Princeton, New Jersey, US). Key exclusion criteria were symptoms or causes of pseudohyperkalemia, diabetic ketoacidosis, cardiac arrhythmia requiring immediate treatment, dialysis, and treatment with non-absorbed antibiotics for hyperammonemia, resins, calcium acetate, calcium carbonate, or lanthanum carbonate within 7 days before the first dose of study drug. See Supplemental Materials for full eligibility criteria.

Patients discontinued the study if they developed serious cardiac arrhythmia, acute HF,

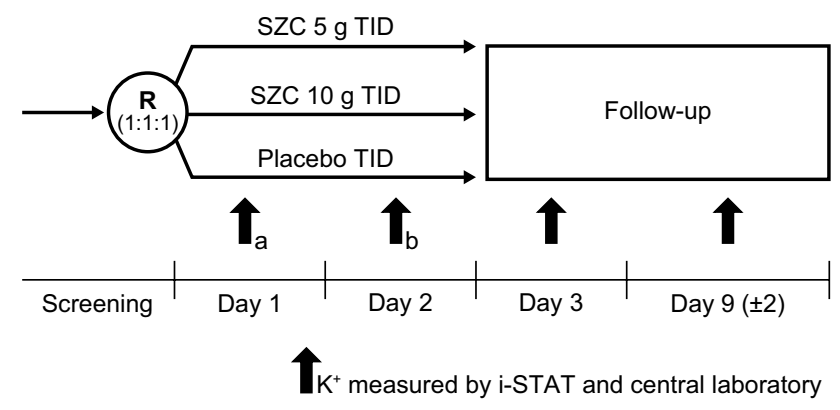

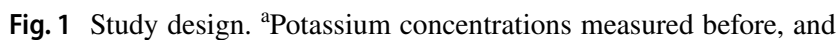
1,2 , and $4 \mathrm{~h}$ after administration of the first dose. ${ }^{\text {b Potassium con- }}$ centrations measured before, and 1 and $4 \mathrm{~h}$ after the first dose. Randomization was stratified according to estimated glomerular filtration rate $<60 \mathrm{~mL} / \mathrm{min} / 1.73 \mathrm{~m}^{2}$ or $\geq 60 \mathrm{~mL} / \mathrm{min} / 1.73 \mathrm{~m}^{2} . K^{+}$potassium, $R$ randomization, $S Z C$ sodium zirconium cyclosilicate, TID three times daily 
or potential hyperkalemia-related electrocardiogram (ECG) changes, or if their i-STAT potassium concentration was $>6.5 \mathrm{mmol} / \mathrm{L}$. Patients discontinued study treatment if they had a confirmed i-STAT potassium concentration of $<3.0 \mathrm{mmol} / \mathrm{L}$. Patients with i-STAT potassium levels $\geq 3.0$ to $\leq 3.4 \mathrm{mmol} / \mathrm{L}$ on days 1 or 2 were to discontinue the study drug for the remainder of the day and return the next day for evaluation to determine whether treatment could be continued.

\section{Assessments}

All potassium samples were measured using both an i-STAT point-of-care device and by the central laboratory. Real-time assessment of potassium by i-STAT was used to determine study eligibility and to guide treatment decisions. Efficacy was evaluated using central laboratory measurements of $\mathrm{sK}^{+}$. Potassium concentrations were measured prior to study drug administration. Patients attended the clinic on day 1 (visit 2), day 2 (visit 3), day 3 (visit 4), and follow-up period (end of study), and fasted for a minimum of $8 \mathrm{~h}$ prior to blood sampling. Safety assessments included AE recording, physical examination, vital signs, laboratory measures, and ECG. Study assessments are detailed in the Supplemental Materials.

During the study, patients could not receive alternative hyperkalemia treatment (including medication). No dietary recommendations or restrictions to limit potassium intake were advised to patients. Insulin use was not restricted; all serum measurements were collected prior to insulin treatment. Oral medications with gastric $\mathrm{pH}$-dependent bioavailability were administered at least $2 \mathrm{~h}$ before or after study drug to mitigate the risk of drug-drug interactions (Supplemental Materials).

\section{Study endpoints}

The primary efficacy endpoint was the exponential rate of change in $\mathrm{sK}^{+}$concentration during the initial $48 \mathrm{~h}$ of treatment. Baseline $\mathrm{sK}^{+}$measurements are summarized in the Supplemental Materials.

The key secondary efficacy endpoint was the proportion of patients achieving normokalemia $\left(\mathrm{sK}^{+} 3.5-5.0 \mathrm{mmol} / \mathrm{L}\right)$ at $48 \mathrm{~h}$ after first dose. Other secondary efficacy endpoints included the proportion of patients achieving normokalemia at $48 \mathrm{~h}$ and at each scheduled $\mathrm{sK}^{+}$assessment time point after start of dosing, mean change from baseline in $\mathrm{sK}^{+}$concentration at all time points post-dose, and time to normalization of $\mathrm{sK}^{+}$concentration.

Safety, tolerability, and treatment compliance were also assessed (Supplemental Materials).

\section{Statistical analysis}

All statistical analyses were performed using SAS ${ }^{\circledR}$ version 9.4 (SAS Institute, Inc, Cary, North Carolina, US). Target sample size calculations are described in the Supplemental Materials.

Efficacy analyses were performed on all randomized patients (full analysis set). Exponential rate of change was analyzed using a random coefficient model. Estimates of treatment difference in slopes (i.e., coefficients for the time by treatment interaction for each dose) are presented for both SZC groups with $95 \%$ CIs as well as two-sided $P$ values for pairwise comparison with placebo. Further details of the statistical methods for efficacy evaluation, including sensitivity and subgroup analyses are summarized in the Supplemental Materials.

Safety analyses were performed in all patients receiving $\geq 1$ dose of study drug (safety analysis set) summarized in the Supplemental Materials.

\section{Results}

\section{Patient disposition and baseline characteristics}

Of 151 patients enrolled, 48 did not meet eligibility criteria; thus, 103 patients were randomized (SZC $5 \mathrm{~g}, n=34$; SZC $10 \mathrm{~g}, n=36$; placebo, $n=33$; Fig. 2). The study was completed by 101 patients (98.1\%); two patients (1.9\%) in the placebo group discontinued after developing $\mathrm{sK}^{+}$ concentrations $>6.5 \mathrm{mmol} / \mathrm{L}$.

Baseline patient characteristics were generally well balanced across treatment groups (Table 1). Mean age was 73.2 years (range $50-89$ years) and $74.8 \%$ were male. Most patients had comorbidities based on medical history, and all patients had received prior and concomitant medications (Table 1).

Most patients (97.1\%) were compliant with the study medication; three patients in the placebo group did not meet treatment compliance parameters.

\section{Exponential rate of change in $\mathrm{sK}^{+}$concentration at $48 \mathrm{~h}$}

At $48 \mathrm{~h}$, exponential rates of change in $\mathrm{sK}^{+}$concentration from baseline were reduced by $0.27 \%$ and $0.51 \%$ per hour with SZC $5 \mathrm{~g}$ and $10 \mathrm{~g}$, respectively. These improvements were significantly greater with SZC $5 \mathrm{~g}(-0.00261)$ and $10 \mathrm{~g}(-0.00496)$ versus placebo (both $P<0.0001$; Table 2). Numerical comparison of the slope values for SZC $5 \mathrm{~g}$ and $10 \mathrm{~g}$ suggested dose dependency.

Results of a sensitivity analysis evaluating the effect of different potassium analytical assays on the primary 


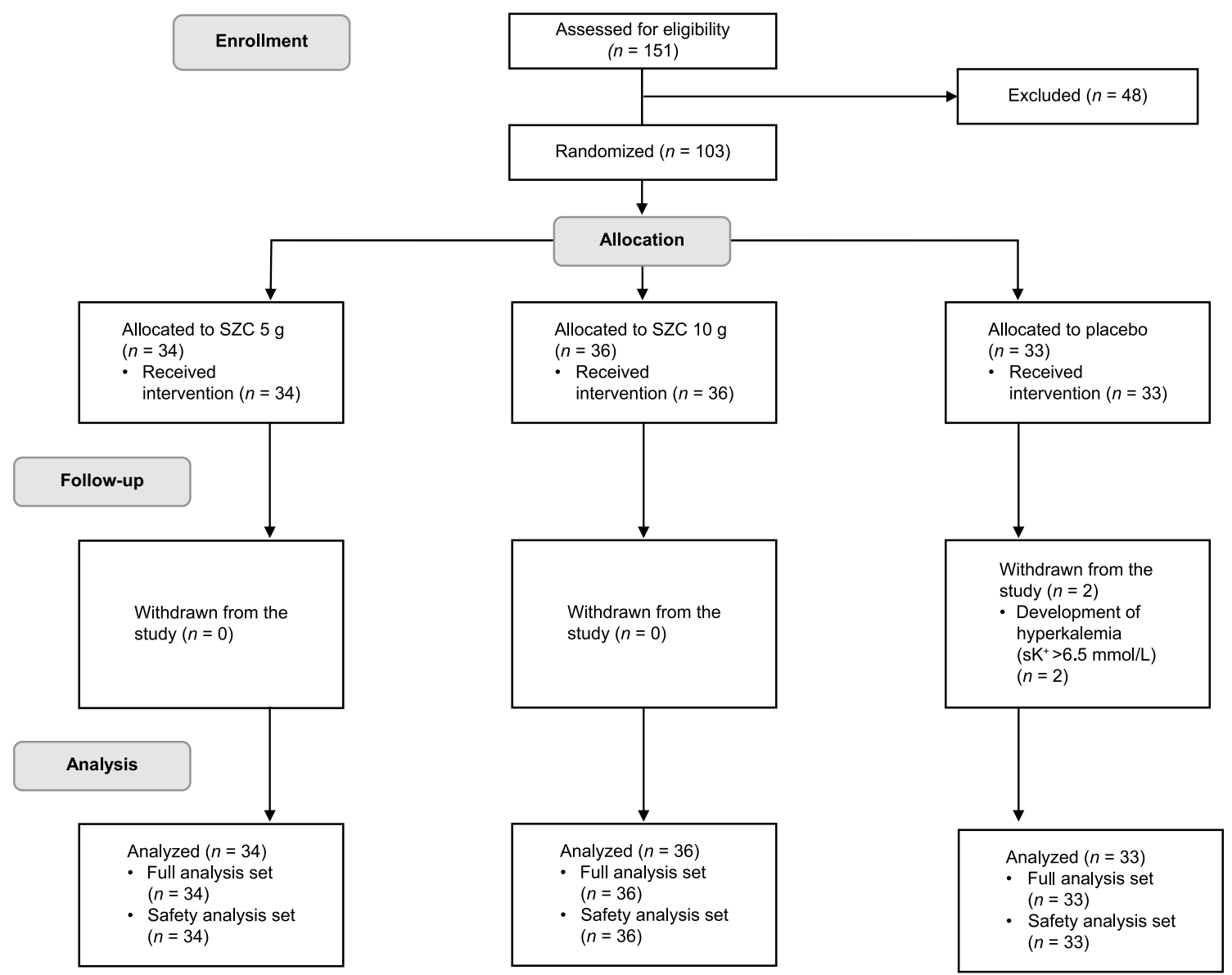

Fig. 2 Study flow diagram. Randomization was stratified according to estimated glomerular filtration rate $<60 \mathrm{~mL} / \mathrm{min} / 1.73 \mathrm{~m}{ }^{2}$ or $\geq 60 \mathrm{~mL} /$ $\mathrm{min} / 1.73 \mathrm{~m}^{2} . s K^{+}$serum potassium, $S Z C$ sodium zirconium cyclosilicate

endpoint were consistent with the primary analysis (Supplemental Table 1).

The exponential rate of change was greater in patients in both SZC groups versus placebo across patient subgroups (Supplemental Table 2).

\section{Proportions of patients with normokalemia}

At $48 \mathrm{~h}$, more patients were normokalemic in both the SZC $5 \mathrm{~g}(85.3 \%)$ and $10 \mathrm{~g}(91.7 \%)$ groups versus placebo (15.2\%; Table 3 ). The odds ratios [OR; $95 \%$ confidence intervals (CI)] relative to placebo were 46.5 (10.1-213.2) and 71.8 (13.5-382.3), respectively (nominal $P<0.0001$ for both). Results of the sensitivity analysis using i-STAT potassium data (Supplemental Table 3) as well as those from the subgroup analysis (Supplemental Fig. 1) were consistent with the overall results.

The odds of achieving normokalemia at $24 \mathrm{~h}$ was greater for the SZC $10 \mathrm{~g}$ group versus placebo: OR 15.3 (95\% CI 4.0-58.7); nominal $P<0.0001$ (Table 3).
Following administration of SZC $10 \mathrm{~g}, 47.2 \%$ of patients attained normokalemia within $1 \mathrm{~h}$, and a higher proportion of patients were normokalemic at all time points throughout the treatment period compared with placebo (Fig. 3). Following SZC $5 \mathrm{~g}$, a higher proportion of patients were normokalemic from $4 \mathrm{~h}$ post-dose onwards compared with placebo. Similar results were achieved across patient subgroups (data not shown).

\section{Mean change from baseline in $\mathrm{sK}^{+}$concentration}

Mean $\mathrm{sK}^{+}$concentration decreased from baseline to a greater degree with SZC $5 \mathrm{~g}$ and $10 \mathrm{~g}$ versus placebo over time (Fig. 4). Differences in the $\mathrm{sK}^{+}$-lowering effect were observed at $1 \mathrm{~h}$ after the first dose of SZC $10 \mathrm{~g}$ (mean change from baseline numerical reduction of $-0.37 \mathrm{mmol} / \mathrm{L}$ for SZC $10 \mathrm{~g} \mathrm{vs}$. - $0.13 \mathrm{mmol} / \mathrm{L}$ for placebo). During study day 2 (from 24 to $48 \mathrm{~h}$ ), numerically greater mean reductions in $\mathrm{sK}^{+}$concentration were observed at all time points in the SZC $10 \mathrm{~g}$ and $5 \mathrm{~g}$ dose groups than with placebo (Fig. 4). Reductions in $\mathrm{sK}^{+}$ 
Table 1 Patient demographics and baseline characteristics (full analysis set)

\begin{tabular}{|c|c|c|c|c|}
\hline Characteristic & SZC $5 \mathrm{~g}(n=34)$ & SZC $10 \mathrm{~g}(n=36)$ & Placebo $(n=33)$ & Total $(N=103)$ \\
\hline Age, years, mean (SD) & $72.4(7.9)$ & $71.1(7.6)$ & $76.1(6.8)$ & $73.2(7.7)$ \\
\hline Male, $n(\%)$ & $26(76.5)$ & $28(77.8)$ & $23(69.7)$ & $77(74.8)$ \\
\hline Japanese race, $n(\%)$ & $34(100)$ & $36(100)$ & $33(100)$ & $103(100)$ \\
\hline Weight, kg, mean (SD) & $63.2(11.6)$ & $64.6(14.7)$ & $61.2(10.7)$ & $63.0(12.5)$ \\
\hline $\mathrm{sK}^{+}$concentration, mmol/L, mean (SD) & $5.6(0.4)$ & $5.5(0.4)$ & $5.7(0.4)$ & $5.6(0.4)$ \\
\hline \multicolumn{5}{|l|}{$\mathrm{sK}^{+}$concentration group, $\mathrm{mmol} / \mathrm{L}, n(\%)$} \\
\hline$<5.3$ & $10(29.4)$ & $12(33.3)$ & $6(18.2)$ & $28(27.2)$ \\
\hline $5.3-5.5$ & $6(17.6)$ & $12(33.3)$ & $12(36.4)$ & $30(29.1)$ \\
\hline$>5.5$ & $18(52.9)$ & $12(33.3)$ & $15(45.5)$ & $45(43.7)$ \\
\hline eGFR, $\mathrm{mL} / \mathrm{min} / 1.73 \mathrm{~m}^{2},{ }^{\mathrm{a}}$ mean $(\mathrm{SD})$ & $24.2(14.3)$ & $29.4(16.6)$ & $24.5(13.5)$ & $26.1(14.9)$ \\
\hline \multicolumn{5}{|l|}{ eGFR group, $\mathrm{mL} / \mathrm{min} / 1.73 \mathrm{~m}^{2},{ }^{\mathrm{a}} n(\%)$} \\
\hline$<15$ & $10(29.4)$ & $9(25.0)$ & $11(33.3)$ & $30(29.1)$ \\
\hline $15-<30$ & $17(50.0)$ & $13(36.1)$ & $11(33.3)$ & $41(39.8)$ \\
\hline $30-<60$ & $7(20.6)$ & $11(30.6)$ & $11(33.3)$ & $29(28.2)$ \\
\hline$\geq 60$ & $0(0.0)$ & $3(8.3)$ & $0(0.0)$ & $3(2.9)$ \\
\hline Serum bicarbonate, $\mathrm{mmol} / \mathrm{L}$, mean $(\mathrm{SD})$ & $19.9(2.8)$ & $20.3(3.2)$ & $19.4(3.2)$ & $\mathrm{NA}^{\mathrm{c}}$ \\
\hline Serum urea nitrogen, mmol/L, mean (SD) & $14.8(6.1)$ & $12.8(5.0)$ & $14.6(6.6)$ & $\mathrm{NA}^{\mathrm{c}}$ \\
\hline \multicolumn{5}{|l|}{ Comorbidity, ${ }^{\mathrm{b}} n(\%)$} \\
\hline Chronic kidney disease & $26(76.5)$ & $26(72.2)$ & $26(78.8)$ & $78(75.7)$ \\
\hline Diabetes & $22(64.7)$ & $24(66.7)$ & $16(48.5)$ & $62(60.2)$ \\
\hline Heart failure & $7(20.6)$ & $3(8.3)$ & $4(12.1)$ & $14(13.6)$ \\
\hline \multicolumn{5}{|l|}{ Concomitant medication use, $n(\%)$} \\
\hline RAASi therapy & $27(79.4)$ & $26(72.2)$ & $27(81.8)$ & $80(77.7)$ \\
\hline Diuretics & $17(50.0)$ & $9(25.0)$ & $11(33.3)$ & $37(35.9)$ \\
\hline
\end{tabular}

$e G F R$ estimated glomerular filtration rate, $N A$ not available, $R A A S i$ renin-angiotensin-aldosterone system inhibitor, $S D$ standard deviation $s K^{+}$ serum potassium, SMQ Standardized Medical Dictionary for Regulatory Activities Queries, SZC sodium zirconium cyclosilicate

${ }^{a}$ eGFR estimated using the equation generated by the Japanese Society of Nephrology, with serum creatinine measured at the randomization visit

${ }^{\mathrm{b}}$ Based on medical history by SMQ (narrow) search (ongoing)

${ }^{\mathrm{c}}$ Not calculated

Table 2 Exponential rate of change in $\mathrm{sK}^{+}$concentration per hour from baseline to $48 \mathrm{~h}$ after administration of SZC (full analysis set)

\begin{tabular}{|c|c|c|c|c|c|c|c|}
\hline \multirow[t]{2}{*}{ Treatment group } & \multicolumn{3}{|c|}{ Exponential rate of change } & \multicolumn{3}{|c|}{ Comparison with placebo } & \multirow[t]{2}{*}{$P$ value } \\
\hline & Estimate & SE & $95 \% \mathrm{CI}$ & Estimate & SE & $95 \% \mathrm{CI}$ & \\
\hline SZC $5 \mathrm{~g}(n=34)$ & -0.00273 & 0.000276 & -0.00328 to -0.00219 & -0.00261 & 0.000385 & -0.00337 to -0.00185 & $<0.0001$ \\
\hline SZC $10 \mathrm{~g}(n=36)$ & -0.00508 & 0.000269 & -0.00561 to -0.00455 & -0.00496 & 0.000380 & -0.00571 to -0.00420 & $<0.0001$ \\
\hline Placebo $(n=33)$ & -0.00012 & 0.000288 & -0.00069 to 0.00045 & - & - & - & - \\
\hline
\end{tabular}

Negative exponential rate of change relative to placebo indicates more rapid reduction (correction) of $\mathrm{sK}^{+}$. Serial $\log _{\mathrm{e}}\left(\mathrm{sK}^{+}\right.$concentration) values from 0 to $48 \mathrm{~h}$ were modeled using a random coefficient model, including fixed effects of intercept, time, time by treatment, and patient-level random effects for time and intercept

$C I$ confidence interval, $S E$ standard error, $s K^{+}$serum potassium, $S Z C$ sodium zirconium cyclosilicate 
Table 3 Proportion of normokalemic patients at 48 and $24 \mathrm{~h}$ after administration of SZC (full analysis set)

\begin{tabular}{|c|c|c|c|c|c|}
\hline \multirow[t]{2}{*}{ Treatment group } & \multirow[t]{2}{*}{ Time point, $\mathrm{h}$} & \multirow{2}{*}{$\begin{array}{l}\text { Patients with nor- } \\
\text { mokalemia, } n(\%)\end{array}$} & \multicolumn{3}{|c|}{ Comparison with placebo ${ }^{a}$} \\
\hline & & & $\overline{\mathrm{OR}}$ & $95 \% \mathrm{CI}$ & $P$ value $^{\mathrm{b}}$ \\
\hline \multirow[t]{2}{*}{ SZC $5 \mathrm{~g}(n=34)$} & 24 & $12(35.3)$ & 1.3 & $0.4-4.3$ & 0.6167 \\
\hline & 48 & $29(85.3)$ & 46.5 & $10.1-213.2$ & $<0.0001$ \\
\hline \multirow[t]{2}{*}{ SZC $10 \mathrm{~g}(n=36)$} & 24 & $30(83.3)$ & 15.3 & $4.0-58.7$ & $<0.0001$ \\
\hline & 48 & $33(91.7)$ & 71.8 & $13.5-382.3$ & $<0.0001$ \\
\hline \multirow[t]{2}{*}{ Placebo $(n=33)$} & 24 & $9(27.3)$ & - & - & - \\
\hline & 48 & $5(15.2)$ & - & - & - \\
\hline
\end{tabular}

Patients with missing $\mathrm{sK}^{+}$concentration data were regarded as not normokalemic

$C I$ confidence interval, $O R$ odds ratio, $s K^{+}$serum potassium, $S Z C$ sodium zirconium cyclosilicate

${ }^{\mathrm{a}}$ Logistic regression model including treatment and baseline $\mathrm{sK}^{+}$concentration as explanatory variables were used

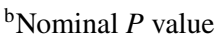

$\operatorname{SZC} 5 \mathrm{~g}(n=34)-\operatorname{SZC} 10 \mathrm{~g}(n=36)-\square-$ Placebo $(n=33)$

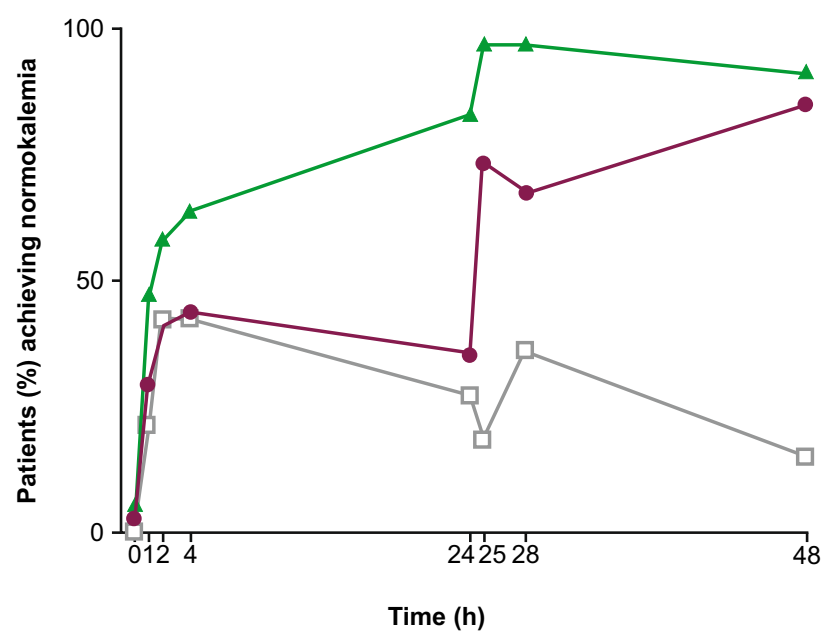

Fig. 3 Proportion of normokalemic patients over time after administration of SZC (full analysis set). Normokalemia defined as $\mathrm{sK}^{+}$ 3.5-5.0 mmol/L. $s K^{+}$serum potassium, $S Z C$ sodium zirconium cyclosilicate

from baseline were observed with SZC regardless of CKD stage, and results were consistent across patient subgroups (data not shown).

\section{Time to normalization of $\mathrm{sK}^{+}$concentration}

Median time to normalization of $\mathrm{sK}^{+}$concentration was shorter with SZC $10 \mathrm{~g}$ versus placebo $(1.8 \mathrm{~h}$ vs. $3.9 \mathrm{~h}$; logrank nominal $P=0.0006$ ), and was similar for the SZC $5 \mathrm{~g}$ and placebo groups $(3.9 \mathrm{~h}$ and $3.9 \mathrm{~h}$, respectively; logrank nominal $P=0.0586$; Supplemental Fig. 2).
- SZC $5 \mathrm{~g}(n=34) \rightarrow \operatorname{SZC} 10 \mathrm{~g}(n=36) \quad-\square-$ Placebo $(n=33)$

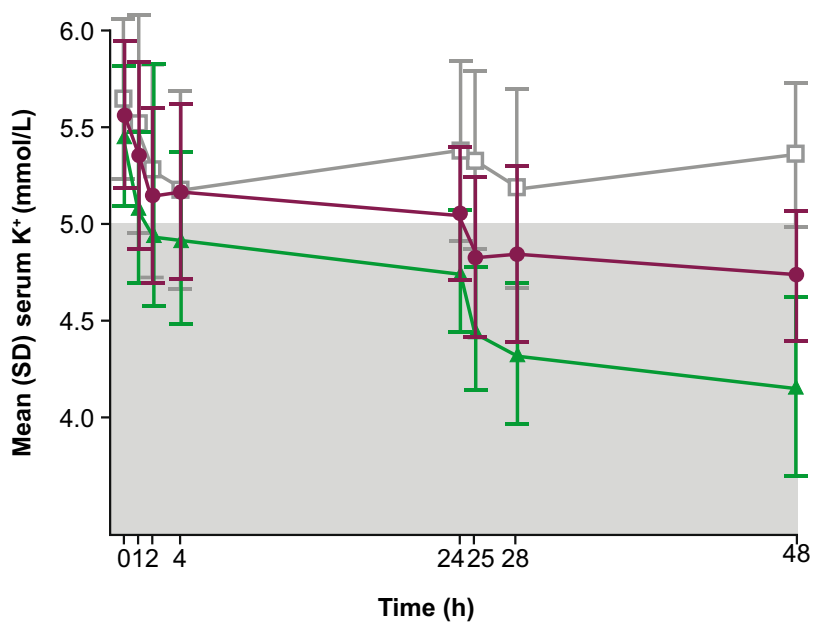

Fig. $4 \mathrm{sK}^{+}$concentrations (mmol/L) over time after administration of SZC (mean \pm SD) (full analysis set). The shaded area of the graph represents the range for normokalemia $\left(\mathrm{sK}^{+} 3.5-5.0 \mathrm{mmol} / \mathrm{L}\right)$. $S D$ standard deviation, $s K^{+}$serum potassium, $S Z C$ sodium zirconium cyclosilicate

\section{Safety}

Treatment-emergent AEs (TEAEs) were reported in four $(11.8 \%)$, five $(13.9 \%)$, and one (3.0\%) patient in the SZC $5 \mathrm{~g}$, SZC $10 \mathrm{~g}$, and placebo groups, respectively (Table 4). All TEAEs were mild. Apart from one patient who experienced five episodes of tremor, AEs were single occurrences. TEAEs considered by the Investigator to be SZCrelated were reported in two $(5.6 \%)$ patients in the SZC $10 \mathrm{~g}$ group (tremor and ventricular extrasystole) and one (2.9\%) patient in the SZC $5 \mathrm{~g}$ group (constipation). No TEAEs of hypokalemia, death, serious AEs, AEs leading to discontinuation, or other AEs deemed significant were reported. 
Table 4 AEs (safety analysis set)

\begin{tabular}{llll}
\hline AEs, $n(\%)$ & SZC 5 g $(n=34)$ & SZC 10 g $(n=36)$ & $\begin{array}{l}\text { Placebo }(n= \\
33)\end{array}$ \\
\hline Any AE & $4(11.8)$ & $5(13.9)$ & $1(3.0)$ \\
Constipation & $1(2.9)$ & $0(0.0)$ & $0(0.0)$ \\
Erythema & $0(0.0)$ & $1(2.8)$ & $0(0.0)$ \\
Hypoglycemia & $0(0.0)$ & $1(2.8)$ & $0(0.0)$ \\
Nephrogenic anemia & $1(2.9)$ & $0(0.0)$ & $0(0.0)$ \\
Respiratory tract infection & $0(0.0)$ & $0(0.0)$ & $1(3.0)$ \\
Tension headache & $0(0.0)$ & $1(2.8)$ & $0(0.0)$ \\
Thirst & $1(2.9)$ & $0(0.0)$ & $0(0.0)$ \\
Tremor & $0(0.0)$ & $1(2.8)$ & $0(0.0)$ \\
Ventricular extrasystoles & $0(0.0)$ & $1(2.8)$ & $0(0.0)$ \\
Viral upper respiratory tract infection & $1(2.9)$ & $0(0.0)$ & $0(0.0)$ \\
SAEs & $0(0.0)$ & $0(0.0)$ & $0(0.0)$ \\
Death & $0(0.0)$ & $0(0.0)$ & $0(0.0)$ \\
Any AE leading to discontinuation of study drug & $0(0.0)$ & $0(0.0)$ & $0(0.0)$ \\
Any causally related AE & $1(2.9)$ & $2(5.6)$ & $0(0.0)$
\end{tabular}

Patients with multiple events in the same category were counted only once in that category. Patients with events in more than one category were counted once in each of those categories. AEs with an onset date on or after first dose of study drug, but on or before day 3, are included as treatment-emergent AEs. Percentages are based on the total numbers of patients in the treatment group $(N)$

$A E$ adverse event, $S A E$ serious adverse event, $S Z C$ sodium zirconium cyclosilicate
No clinically relevant trends were apparent in the mean changes from baseline in hematology values, except for $\mathrm{sK}^{+}$. Dose-related increases in mean bicarbonate levels were observed with SZC $5 \mathrm{~g}(0.64 \mathrm{mmol} / \mathrm{L})$ and SZC $10 \mathrm{~g}$ $(1.49 \mathrm{mmol} / \mathrm{L})$ compared with placebo $(-0.46 \mathrm{mmol} / \mathrm{L})$ on study day 3. Two patients in the SZC $10 \mathrm{~g}$ group had a lowest $\mathrm{sK}^{+}$concentration of $<3.5 \mathrm{mmol} / \mathrm{L}$, based on central laboratory assessment, during day 1 to day 3 ; one of the two patients developed $\mathrm{sK}^{+}$concentration $<3.0 \mathrm{mmol} / \mathrm{L}$. Values returned to within the normal range by 6 days after dosing. No TEAEs were reported in either patient.

No clinically relevant dose-related changes from baseline in body weight, blood pressure, or heart rate were observed. An overall mean increase from baseline in QTc (corrected by Bazett's, QTcB) was seen on day 3 of $8.8 \mathrm{~ms}$ (SZC $5 \mathrm{~g}$ ) and $15.6 \mathrm{~ms}$ (SZC $10 \mathrm{~g}$ ), compared with a decrease of $0.6 \mathrm{~ms}$ with placebo. The proportions of patients who experienced a change in QTcB interval $>30 \mathrm{~ms}$ on study day 3 were: SZC 5 g, 5.9\%; SZC 10 g, 16.7\%; and placebo, $0.0 \%$. No abnormal ECG findings were reported for either of the two patients who developed transient hypokalemia.

\section{Discussion}

This is the first randomized controlled study to report the efficacy and safety of different doses of SZC in Japanese patients with hyperkalemia. SZC was effective in reducing $\mathrm{sK}^{+}$, supporting the use of $\mathrm{SZC}$ in this population. The efficacy endpoints evaluated were consistent with those from previous phase 3 studies of SZC [18, 20], enabling an indirect comparison of efficacy across different populations.

Our study met its primary efficacy endpoint; both SZC $5 \mathrm{~g}$ and $10 \mathrm{~g}$ resulted in significantly greater exponential decreases in $\mathrm{sK}^{+}$concentration from baseline at $48 \mathrm{~h}$ versus placebo. The exponential rate of change was selected as a more clinically relevant endpoint than absolute change from baseline, since it incorporates the time to onset of effect and all $\mathrm{sK}^{+}$measurements throughout the $48 \mathrm{~h}$. The reductions in this study are comparable with those seen in previous phase 3 studies of SZC (i.e., $~ 0.2-0.3 \%$ per hour) [18, 20].

The results of the secondary efficacy analyses support the primary analysis and indicate that SZC is effective for the rapid correction of $\mathrm{sK}^{+}$. Following administration of SZC $10 \mathrm{~g}$, reductions in $\mathrm{sK}^{+}$concentration were observed as early as $1 \mathrm{~h}$ after baseline, median time to normalization was $<2 \mathrm{~h}$, and most patients were normokalemic at $24 \mathrm{~h}$. Consistent with phase 3 studies of SZC in the non-Japanese population, almost all patients who received SZC $10 \mathrm{~g}$ (91.7\%) were normokalemic at $48 \mathrm{~h}[18,20]$. Furthermore, our results suggest dose-dependent efficacy, with SZC $10 \mathrm{~g}$ being more efficacious in normalizing $\mathrm{sK}^{+}$than $5 \mathrm{~g}$, as observed previously $[18,20,21]$. These results were achieved without dietary restriction of potassium intake.

Treatment with placebo resulted in an unsustained reduction in mean $\mathrm{sK}^{+}$concentration, with the lowest measurements in the placebo group observed $4 \mathrm{~h}$ post-administration. Acute reduction of $\mathrm{sK}^{+}$within the first $4 \mathrm{~h}$ of placebo 
administration has been observed in an earlier study of SZC [18]. The mechanism of this reduction is unknown, and could possibly reflect the circadian rhythm of $\mathrm{sK}^{+}$concentration [28] or abrupt changes in diet and daily routine due to the interventions within the clinical trial environment.

The overall safety and tolerability profile for SZC in the first $48 \mathrm{~h}$ of treatment was favorable, consistent with that observed in the non-Japanese population described previously; no new safety concerns were identified $[18,19]$. Despite the $\mathrm{sK}^{+}$-lowering effects of SZC, no TEAEs of hypokalemia were reported. Two patients experienced transient $\mathrm{sK}^{+}<3.5 \mathrm{mmol} / \mathrm{L}$ following treatment with $10 \mathrm{~g} \mathrm{SZC}$; however, normokalemia was re-established within 6 days. No patients reported TEAEs of edema, which have been observed in previous clinical trials [23, 24]. The increase in QTc interval observed in patients treated with SZC was considered clinically insignificant and was consistent with changes reported in a previous phase 3 study of SZC [18]. QT interval is known to be shortened in hyperkalemia and to lengthen with the decreasing $\mathrm{sK}^{+}$concentration as hyperkalemia is corrected [29]. Overall, the efficacy and tolerability data for SZC in the Japanese population suggest that acute SZC treatment for $48 \mathrm{~h}$, at the doses recommended, is a valid treatment option for hyperkalemia in the Japanese population.

Hyperkalemia is common in patients receiving RAASi [3] and can prevent at-risk patients (e.g., those with HF or CKD) from receiving the optimal dose of RAASi required to improve survival. SZC normalized $\mathrm{sK}^{+}$in patients receiving RAASi, suggesting that SZC may avoid the need for dose reduction or discontinuation of RAASi in patients experiencing hyperkalemia.

Patients with $\mathrm{CKD}, \mathrm{HF}$, and diabetes are prone to hyperkalemia [2, 3, 6, 7]. As such, our study included patients with many concomitant diseases and treatments; proportions of patients at baseline with comorbid CKD, diabetes, or receiving RAASi were high, reflecting their real-world prevalence among Japanese patients with hyperkalemia [1]. This is also consistent with the study groups included in phase 3 studies of SZC in the non-Japanese population $[18,20,21]$. Fewer patients in our study had HF at baseline compared with other studies of SZC $[18,20]$, potentially reflecting the lower rate of HF typically seen in Japanese patients compared with patients from other countries [30]. Our study can, therefore, be considered representative of the general Japanese population of patients with hyperkalemia.

Limitations include, first, that the study was conducted among ambulatory patients, and patients who had potassium concentrations $>6.5 \mathrm{mmol} / \mathrm{L}$ or required dialysis were excluded. Therefore, the efficacy of SZC in these groups and in hospitalized patients among the Japanese population could not be determined. Second, clinical endpoints other than $\mathrm{sK}^{+}$concentration were not assessed. Finally, the efficacy of maintenance therapy with SZC was not assessed. However, the efficacy of SZC in the dialysis [31] and emergency settings [32], as well as the impact of SZC on RAASi dosing [22], in predominantly non-Asian populations has been reported previously. Furthermore, the short-term study duration reflects the urgency with which hyperkalemia needs to be corrected and the rapidity with which SZC exerts its effects. Further studies have been conducted to evaluate the long-term efficacy and tolerability of SZC as well as the optimal SZC dose required for maintenance therapy in the Japanese population (NCT03172702).

In conclusion, SZC at both $5 \mathrm{~g}$ and $10 \mathrm{~g}$ given TID for $48 \mathrm{~h}$ was efficacious in reducing $\mathrm{sK}^{+}$in Japanese patients with hyperkalemia and provided rapid attainment of normokalemia. SZC was well tolerated and no new safety concerns were identified. The results support the approval of SZC for the management of hyperkalemia in Japanese patients.

Acknowledgements This study was funded by AstraZeneca. The authors would like to thank the patients, their families, and all investigators involved in this study. Medical writing support was provided by Shaun W. Foley, BSc (Hons) CMPPTM, and editorial support was provided by Bethany King, BSc (Hons), both of Core Medica, London, UK, supported by AstraZeneca according to Good Publication Practice guidelines (http://annals.org/aim/article/2424869/good-publi cation-practice-communicating-company-sponsored-medical-researchgpp3). The sponsor was involved in the study design and collection, analysis, and interpretation of data, as well as data checking of information provided in the manuscript. However, ultimate responsibility for opinions, conclusions, and data interpretation lies with the authors.

Author contributions NK, HK, and TY designed the study. NK, TN, TO, TI, YS, TO, YS, and HM collected the data. NK, TI, YS, YS, HK, and NS performed the data analysis and interpretation. All authors critically reviewed the manuscript, approved the final version, and accept accountability for the overall work.

Funding This study was funded by AstraZeneca.

\section{Compliance with ethical standards}

Conflict of interest $\mathrm{N}$ Kashihara has received consulting fees from AstraZeneca and has received research grants from AstraZeneca and the Japan Agency for Medical Research and Development. Y Saka, T Nishio, T Osonoi, T Imasawa, T Ohtake, H Mizuno, and Y Shibagaki have no conflicts of interest to disclose. H Kim, T Yajima, and N Sarai are employees of AstraZeneca K.K.

Ethical standards All procedures performed in this study were approved by the institutional review board at each participating study site and were in compliance with the 1964 Helsinki Declaration and its later amendments or comparable ethical standards. 
Informed consent Informed consent was obtained from all individual participants included in the study.

Data sharing statement Data underlying the findings described in this manuscript may be obtained in accordance with AstraZeneca's data sharing policy described at https://astrazenecagroup-dt.pharmacm. com/DT/Home.

Open Access This article is licensed under a Creative Commons Attribution 4.0 International License, which permits use, sharing, adaptation, distribution and reproduction in any medium or format, as long as you give appropriate credit to the original author(s) and the source, provide a link to the Creative Commons licence, and indicate if changes were made. The images or other third party material in this article are included in the article's Creative Commons licence, unless indicated otherwise in a credit line to the material. If material is not included in the article's Creative Commons licence and your intended use is not permitted by statutory regulation or exceeds the permitted use, you will need to obtain permission directly from the copyright holder. To view a copy of this licence, visit http://creativecommons.org/licenses/by/4.0/.

\section{References}

1. Kashihara N, Kohsaka S, Kanda E, Okami S, Yajima T. Hyperkalemia in real-world patients under continuous medical care in Japan. Kidney Int Rep. 2019;4:1248-60.

2. Takaichi K, Takemoto F, Ubara Y, Mori Y. Analysis of factors causing hyperkalemia. Intern Med. 2007;46(12):823-9.

3. Juurlink DN, Mamdani MM, Lee DS, Kopp A, Austin PC, Laupacis A, et al. Rates of hyperkalemia after publication of the randomized aldactone evaluation study. N Engl J Med. 2004;351(6):543-51.

4. Ben Salem C, Badreddine A, Fathallah N, Slim R, Hmouda H. Drug-induced hyperkalemia. Drug Saf. 2014;37(9):677-92.

5. Mattu A, Brady WJ, Robinson DA. Electrocardiographic manifestations of hyperkalemia. Am J Emerg Med. 2000;18(6):721-9.

6. Jain N, Kotla S, Little BB, Weideman RA, Brilakis ES, Reilly RF, et al. Predictors of hyperkalemia and death in patients with cardiac and renal disease. Am J Cardiol. 2012;109(10):1510-3.

7. An JN, Lee JP, Jeon HJ, Kim DH, Oh YK, Kim YS, et al. Severe hyperkalemia requiring hospitalization: predictors of mortality. Crit Care. 2012;16(6):R225.

8. Hughes-Austin JM, Rifkin DE, Beben T, Katz R, Sarnak MJ, Deo $\mathrm{R}$, et al. The relation of serum potassium concentration with cardiovascular events and mortality in community-living individuals. Clin J Am Soc Nephrol. 2017;12(2):245-52.

9. Goyal A, Spertus JA, Gosch K, Venkitachalam L, Jones PG, Van den Berghe $\mathrm{G}$, et al. Serum potassium levels and mortality in acute myocardial infarction. JAMA. 2012;307(2):157-64.

10. Collins AJ, Pitt B, Reaven N, Funk S, McGaughey K, Wilson D, et al. Association of serum potassium with all-cause mortality in patients with and without heart failure, chronic kidney disease, and/or diabetes. Am J Nephrol. 2017;46(3):213-21.

11. Nakamura T, Fujisaki T, Miyazono M, Yoshihara M, Jinnouchi H, Fukunari K, et al. Risks and benefits of sodium polystyrene sulfonate for hyperkalemia in patients on maintenance hemodialysis. Drugs R D. 2018;18(3):231-5.

12. Saito Y, Yamamoto H, Nakajima H, Takahashi O, Komatsu Y. Incidence of and risk factors for newly diagnosed hyperkalemia after hospital discharge in non-dialysis-dependent CKD patients treated with RAS inhibitors. PLoS One. 2017;12(9):e0184402.
13. Harel Z, Harel S, Shah PS, Wald R, Perl J, Bell CM. Gastrointestinal adverse events with sodium polystyrene sulfonate (Kayexalate) use: a systematic review. Am J Med. 2013;126(3):264 e9-264 e24.

14. Sterns RH, Rojas M, Bernstein P, Chennupati S. Ion-exchange resins for the treatment of hyperkalemia: are they safe and effective? J Am Soc Nephrol. 2010;21(5):733-5.

15. Castillo-Cejas MD, de-Torres-Ramirez I, Alonso-Cotoner $\mathrm{C}$, Colonic necrosis due to calcium polystyrene sulfonate (Kalimate) not suspended in sorbitol. Rev Esp Enferm Dig. 2013;105(4):232-4.

16. Tongyoo A, Sriussadaporn E, Limpavitayaporn P, Mingmalairak C. Acute intestinal obstruction due to Kalimate, a potassiumlowering agent: a case report and literature review. J Med Assoc Thai. 2013;96(12):1617-20.

17. Stavros F, Yang A, Leon A, Nuttall M, Rasmussen HS. Characterization of structure and function of ZS-9, a K+ selective ion trap. PLoS One. 2014;9(12):e114686-e.

18. Packham DK, Rasmussen HS, Lavin PT, El-Shahawy MA, Roger $\mathrm{SD}$, Block G, et al. Sodium zirconium cyclosilicate in hyperkalemia. N Engl J Med. 2015;372(3):222-31.

19. Ash SR, Singh B, Lavin PT, Stavros F, Rasmussen HS. A phase 2 study on the treatment of hyperkalemia in patients with chronic kidney disease suggests that the selective potassium trap, ZS-9, is safe and efficient. Kidney Int. 2015;88(2):404-11.

20. Kosiborod M, Rasmussen HS, Lavin P, Qunibi WY, Spinowitz $\mathrm{B}$, Packham D, et al. Effect of sodium zirconium cyclosilicate on potassium lowering for 28 days among outpatients with hyperkalemia: the HARMONIZE randomized clinical trial. JAMA. 2014;312(21):2223-33.

21. Anker SD, Kosiborod M, Zannad F, Piña IL, McCullough PA, Filippatos $\mathrm{G}$, et al. Maintenance of serum potassium with sodium zirconium cyclosilicate (ZS-9) in heart failure patients: results from a phase 3 randomized, double-blind, placebo-controlled trial. Eur J Heart Fail. 2015;17(10):1050-6.

22. Spinowitz BS, Fishbane S, Pergola PE, Roger SD, Lerma EV, Butler J, et al. Sodium zirconium cyclosilicate among individuals with hyperkalemia: A 12-month phase 3 study. Clin J Am Soc Nephrol. 2019;14(6):798-809.

23. AstraZeneca. Annex I-Summary of product characteristics. Lokelma: EPAR—Product Information; 2018. https://www.ema. europa.eu/en/documents/product-information/lokelma-epar-produ ct-information_en.pdf.

24. AstraZeneca. LOKELMA. Highlights of prescribing information. 2018. https://www.accessdata.fda.gov/drugsatfda_docs/label /2018/207078s000lbl.pdf

25. AstraZeneca. Lokelma approved in Japan for the treatment of hyperkalaemia. 2020 [cited 202004 April]. https://www.astra zeneca.com/media-centre/press-releases/2020/lokelma-appro ved-in-japan-for-the-treatment-of-hyperkalaemia.html.

26. Drewnowski A, Rehm CD, Maillot M, Mendoza A, Monsivais $\mathrm{P}$. The feasibility of meeting the WHO guidelines for sodium and potassium: a cross-national comparison study. BMJ Open. 2015;5(3):e006625-e.

27. Zhou BF, Stamler J, Dennis B, Moag-Stahlberg A, Okuda N, Robertson $\mathrm{C}$, et al. Nutrient intakes of middle-aged men and women in China, Japan, United Kingdom, and United States in the late 1990s: the INTERMAP study. J Hum Hypertens. 1990s; 17:623-30.

28. Schmidt ST, Ditting T, Deutsch B, Schutte R, Friedrich S, Kistner I, et al. Circadian rhythm and day to day variability of serum potassium concentration: a pilot study. J Nephrol. 2015;28(2):165-72.

29. Diercks DB, Shumaik GM, Harrigan RA, Brady WJ, Chan TC. Electrocardiographic manifestations: electrolyte abnormalities. J Emerg Med. 2004;27(2):153-60. 
30. Ponikowski P, Anker SD, AlHabib KF, Cowie MR, Force TL, Hu $S$, et al. Heart failure: preventing disease and death worldwide. ESC Heart Failure. 2014;1(1):4-25.

31. Fishbane S, Ford M, Fukagawa M, McCafferty K, Rastogi A, Spinowitz B, et al. A phase $3 \mathrm{~b}$, randomized, double-blind, placebo-controlled study of sodium zirconium cyclosilicate for reducing the incidence of predialysis hyperkalemia. J Am Soc Nephrol. 2019;30(9):1723-33.
32. Peacock WF, Rafique Z, Vishnevskiy K, Michelson E, Vishneva E, Zvereva T, et al. Emergency potassium normalization treatment including sodium zirconium cyclosilicate: a phase II, randomized, double-blind, placebo-controlled study (ENERGIZE). Acad Emerg Med. 2020;27(6):475-86.

Publisher's Note Springer Nature remains neutral with regard to jurisdictional claims in published maps and institutional affiliations. 